\title{
An Experimental Comparison of Approaches to Training Insight*
}

\author{
James N. MacGregor \\ University of Victoria, Canada \\ E-mail address: jmacgreg@uvic.ca

\section{Jennifer Walinga} \\ Royal Roads University, Victoria, B.C., Canada \\ E-mail address: Jennifer.walinga @ royalroads.ca
}

\author{
John Barton Cunningham \\ University of Victoria, Canada \\ E-mail address: bcunning@uvic.ca
}

\section{ARTICLE INFO}

\section{Keywords:}

Insight

Problem solving

Creativity training

\section{Article history:}

Received 07 August 2019

Received in revised form 28 October 2019

Accepted 27 December 2019

ISSN: 2354-0036

DOI: 10.1515/ctra-2019-0010

A B S TR A C T

The purpose of the research was to investigate different types of training in insight problem solving. In doing so, we reviewed the literature on experimental tests of procedures for training insight problem solving. The results revealed that most procedures focused either on restructuring or divergent thinking, and provided some evidence for the effectiveness of both approaches. However, we found no studies that compared the effects of the two approaches. The article reports two experiments that compared different training procedures based on restructuring and divergent thinking. For the latter, the methods focused separately on fluency, flexibility and originality training. The first experiment compared a restructuring approach with fluency training and a placebo control condition. The results indicated that the restructuring training was significantly more effective than the others, but only when instructions were verbal, not in script form. The second experiment compared restructuring training with flexibility, fluency and originality training, all presented in script form, and the results indicated that the restructuring training was significantly more effective than both fluency training and flexibility training. Implications for future research are discussed.

\section{INTRODUCTION}

Insights - commonly associated with the Aha! experience - are considered to be the sudden realization of being able to solve a problem or find a novel route to reach a goal. One of the most central questions in the psychology of thinking concerns the process by which insight occurs. "Why is it that some people, when they are faced with problems, get clever

\footnotetext{
* The research was partially supported by grants from NSERC and SSHRC. The contact author is James MacGregor, School of Public Administration, University of Victoria, BC, Canada.
} 
ideas, make inventions and discoveries? What happens, what are the processes that lead to such solutions?" (Luchins \& Luchins, 1970, p. 1). These questions, asked by the Gestalt psychologist, Max Wertheimer, in the 1930's, continue to be a driving force in searching for how people solve problems, make discoveries, or make decisions. Are insights and discoveries sparked by an event, or a hint, something which forces us to think in new ways? Are some people more flexible or original in their thinking and able to recognize that constraints can really be worked around?

Insights are thought to be at the heart of the discovery process, when the problem solver unravels a way to solve a problem which he or she was previously unable to solve. Examples of such discoveries might be Banting and Best's discovery of insulin for treating diabetes (Hume, 2001), Watson and Crick's idea of a double helix organization of DNA (Watson, 1968) or George de Mestral's unearthing of how the burrs that clung to his clothes might be used to develop a hook and loop style of binding later called Velcro.

There has been a resurgence of interest in insight over the last three decades, following a seminal edited collection (Sternberg \& Davidson, 1995). A number of new theoretical developments appeared, in the form of Representational Change Theory (Knoblich, Ohlsson, Heider \& Rhenius 1999), Criterion for Satisfactory Progress Theory (MacGregor, Ormerod, \& Chronicle, 2001) and Redistribution Theory (Ohlsson, 2011). New methods have been developed for measuring insight-related phenomena. Some have expanded the available repertoire of test problems, such as compound remote associates (Bowden \& Jung-Beeman, 2003) and rebus puzzles (MacGregor \& Cunningham, 2008). Others have introduced novel procedures, such as feeling-of-warmth ratings (Metcalfe, 1996), and methods to identify brain activity associated with insight (Kounios et al., 2006; Luo, Niki, \& Phillips, 2004). As part of this general increase in activity, research has addressed whether insight problem solving can be promoted, and this is the main concern of the present research.

Many organizations make substantial investments in different kinds of training as an effort to improve more creativity in developing ideas (Rose \& Lin, 1984; Scott, Leritz, \& Mumford, 2004; Torrance, 1972) and insight problem solving seems to underlie some popular approaches for encouraging insight or thinking differently (de Bono, 1972, 1972). A number of experimental studies have now investigated effects of instruction, training and hints on people's success in solving insight problem solving (Ansburg \& Dominowski, 2000; Davidson \& Sternberg, 1984; Duncan, 1961; Lung \& Dominowski, 1985; Maier, 1933). Training is often of different types focusing on creative thinking (Rose \& Lin, 1984; Scott, Leritz, \& Mumford, 2004; Torrance, 1972) and finding insightful solutions to problems (Ansburg \& Dominowski, 2000; Chrysikou, 2006; Davidson \& Sternberg, 1984). We report 
two experiments that compared two theoretically different training procedures, contrasting training which emphasizes a Gestalt based restructuring approach with procedures that focused separately on creativity training in encouraging fluency, flexibility and originality, three of the main factors of divergent thinking (Guilford, 1950).

\section{REVIEW OF DIFFERENT TRAINING APPROACHES}

While there has been a long-standing interest in training creativity in general, studies of training insight problem solving have been much rarer. In this, section we briefly review (a) evaluations of creativity training in general, followed by (b) reports of insight training, specifically.

\section{Creativity training}

As far back as 1972, Torrance published a summary of over 140 studies on creativity training (Torrance, 1972), the majority of which measured creativity using Torrance Tests of Creative Thinking (TTCT). Subsequently a number of systematic reviews and metaanalyses have been reported (Ma, 2006; Mansfield, Busse, \& Krepelka, 1978; Moga, Butler, Hetland, \& Winner, 2000; Rose \& Lyn, 1984; Scott, Leritz, \& Mumford, 2004).

Mansfield et al. (1978) evaluated the results of almost 40 studies, involving a dozen different creativity programs, the majority of which placed "...primary and sometimes exclusive emphasis on divergent thinking..." (p. 518). They concluded that the evidence supported "...the view that creativity can be trained..." (p. 531), but noted that the evidence for transfer of training was limited, as the majority of training programs emphasized divergent thinking and measured effectiveness in terms of gains in divergent thinking. Rose and Lyn (1984) conducted a meta-analysis on the results of over 40 studies, all of which involved the TTCT as dependent variable, and reported a moderate average effect size.

Moga et al (2000) conducted three meta-analyses of studies on the effects of study -ing visual arts on creative thinking. In all, eight studies were included in the metaanalyses, the majority of which used either the TTCT or a test of fluency as the measure of creativity.

Scott et al. (2004) reported a meta-analysis of 70 training studies which yielded 97 effect sizes. Dependent variables were classified into four categories, divergent thinking (fluency, flexibility, originality, elaboration), accounting for $38 \%$ of effect sizes, problem solving (29\%), performance (16\%), and attitude/behavior (16\%). Average effect sizes for the four categories of dependent variable were $.75, .84, .35$ and .24 for divergent thinking, problem solving, performance and attitude/behavior, respectively.

Finally, the meta-analysis reported by Ma (2006) was based on 34 studies involving over 250 effect sizes, with an overall mean of .77, a moderate, and borderline large, 
effect size. Twelve separate dependent variables were analyzed, the majority being either fluency or originality, which together accounted for over $60 \%$ of the effect sizes.

Taken together, the results are consistent with the early conclusions of Mansfield et al., (1978) that creativity can be trained, but that the bulk of the evidence is based on training divergent thinking and measuring the results in terms of its component factors, of fluency, flexibility and originality. There was little or no evidence in any of the systematic reviews or meta-evaluations that specifically addressed insight problem solving and whether or not it is amenable to training. Next, we turn to this issue, with a summary and review of the limited literature on training insight problem solving.

\section{Insight training}

The resurgence of research on insight problem solving over the past several decades has brought with it a growing interest in developing methods to improve insight performance. In a review, Chu and MacGregor (2011) identified five approaches to influencing insight performance - training (e.g. Ansburg \& Dominowski, 2000; Chrysikou, 2006), providing hints (e.g. Burke, Maier, \& Hoffman, 1966; Chronicle, Ormerod, \& MacGregor, 2001; Kokinov, Hadjiilieva, \& Yoveva, 1997, using problem analogs (e.g. Gick \& Holyoak, 1980; Ormerod, Fioratou, Chronicle, \& MacGregor, 2006), manipulating number of moves (e.g. Ash \& Wiley, 2006; MacGregor, Ormerod, \& Chronicle, 2001), and requiring concurrent verbalization (e.g. Ball \& Stevens, 2009; Berardi-Coletta et al., 1995). To these, Patrick and Ahmed (2014) added a sixth, in the form of manipulating the situation, such as allowing an opportunity for incubation. Some of these approaches are quite specific, as in the case of hints and problem analogs, where the aid to solution is tailored to a particular instance of an insight problem. Other approaches may apply more generally, such as incubation and training. The present research is concerned with the last of these approaches. In this, we understand "training" to involve a set of instructions that are sufficiently general that they are able to facilitate solutions when later confronted with previously unfamiliar insight problems (e.g. Patrick \& Ahmed, 2014).

\section{Literature Search}

In our search for relevant studies we adopted the following criteria. First, the research had to include an experimental comparison which involved the manipulation of training as defined above. Second, the dependent variable(s) had to include performance on at least one insight problem. Third, we limited the search to peer reviewed journals.

We began by examining the studies cited by Chu and MacGregor (2011), which resulted in five references, four of which met our criteria for inclusion. Next, we examined the citation lists from each of these, which led to six additional references, four of which met the criteria. Most of these were older, and none of their reference lists resulted 
in new candidate studies. Finally, we conducted a full-text search of the ERIC, PsycINFO, and PsycARTICLES databases using the search string "insight" problem solving" AND training. After removing articles that had been previously found or that did not meet the criteria, nine of these remained. In total, the search procedure resulted in 17 articles reporting experimental studies of insight training.

\section{Classification of insight training programs}

The training programs and procedures used in each study were examined and classified into the following categories.

1. Restructuring: The procedure primarily focuses on problem reformulation, overcoming impasses or barriers to solution through techniques such as constraint relaxation, questioning assumptions, mindfulness.

2. Divergence: The procedure primarily focuses on generating alternatives, including multiple uses, unusual uses, ad hoc categories, multiple moves.

3. Other: any training procedure that does not clearly focus on restructuring or divergent thinking.

Table 1 summarizes the 17 articles, which together yielded 30 experiments. For each study, the columns of the table show: the source; the focus of training; the performance measures used; the experimental comparisons involved; a brief summary of findings. The sources are reported in chronological order, from earliest to most recent.

In terms of training focus, the Table indicates that the majority of studies used a form of restructuring training, which was tested in 21 of the 30 experiments. Divergent thinking was the next most prevalent form of training, represented in eight. It should be noted that the distinction between the two was not always absolute, and there were instances where one may have contained elements of the other. For example, the "overinclusive thinking training" applied in Chiu (2015), considered a form of flexibility training, might also be viewed as a means of inducing constraint-relaxation. Also, the listing of opposites procedure used in the Bianchi et al., (2019) study, has similarities with some methods of fluency training. However, we believe that the classification, while imperfect, provides a guide to the main types of training and their relative frequencies.

The experimental tests fell into one of three main types: two group comparison, typically, training vs. control (11); multigroup comparison (16); factorial design with two independent variables (3).

Of the 11 two-group comparisons, the results of the earliest three are difficult to interpret. Maier (1933) did not report statistical tests for his two experiments, while Maltzman's et al., (1958) finding of no significant difference between two training methods is 
uninterpretable in the absence of a control condition. All of the remaining eight two-group comparisons resulted in significant increases in solution rates as a result of training, seven using restructuring training.

Of the 16 multigroup studies, 13 reported significant positive effects of training, nine associated with restructuring, and four with divergence. The three non-significant results all used divergence training, although all three were from the same study using a single spatial insight problem as the test (Duncan, 1961).

Finally, all three experiments using factorial comparisons reported some significant positive effect of restructuring training, but in each case moderated by the effects of the other independent variable.

In total, of the 27 interpretable experimental comparisons in Table 1, 24 (89\%) showed some significant positive effect of the training intervention. Of these, 19 of the 21 instances testing restructuring training had significantly positive results $(90 \%)$, while four of the seven tests of divergence were positive (57\%). In all, the results provide fairly consistent evidence that insight problem solving can be improved through instructional training. In addition, the limited evidence available suggests that training in restructuring may be more effective than training in divergent thinking.

The experiments reported in Table 1 had a number of similarities and differences, two of which motivated the two studies reported here. The first is in the comparison groups that the experiments employed, while the second is in the format of instruction that they used. 


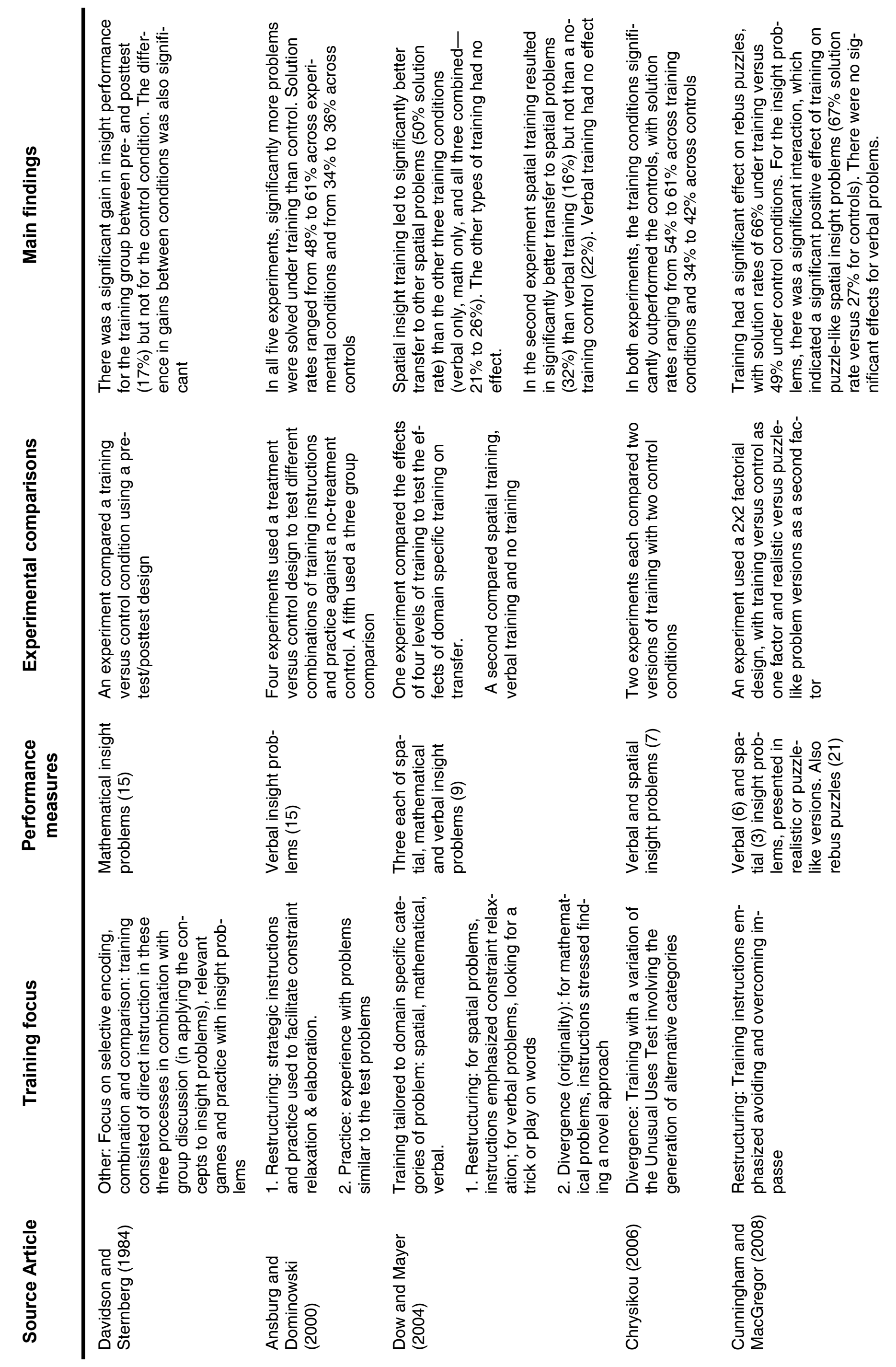




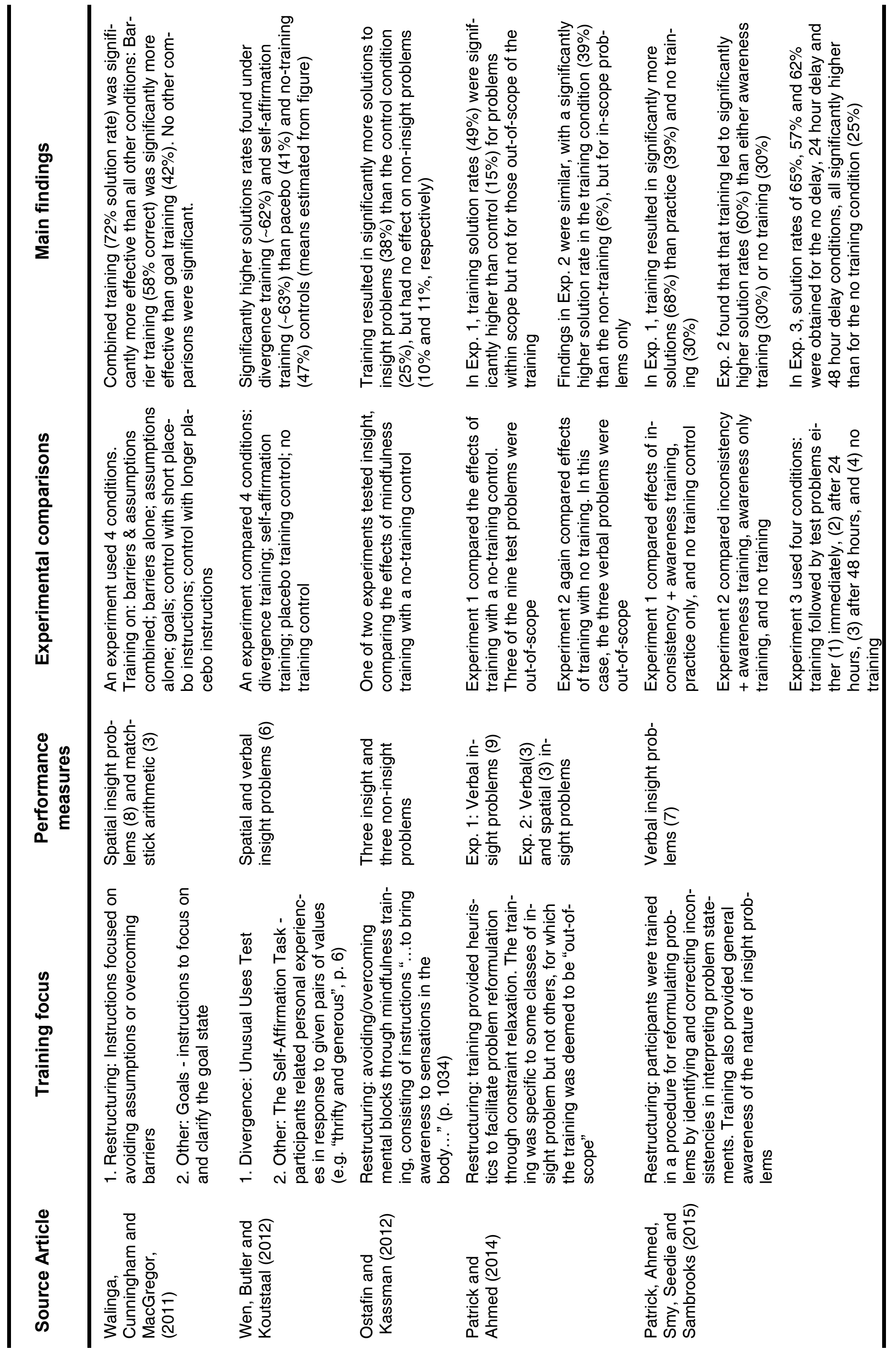




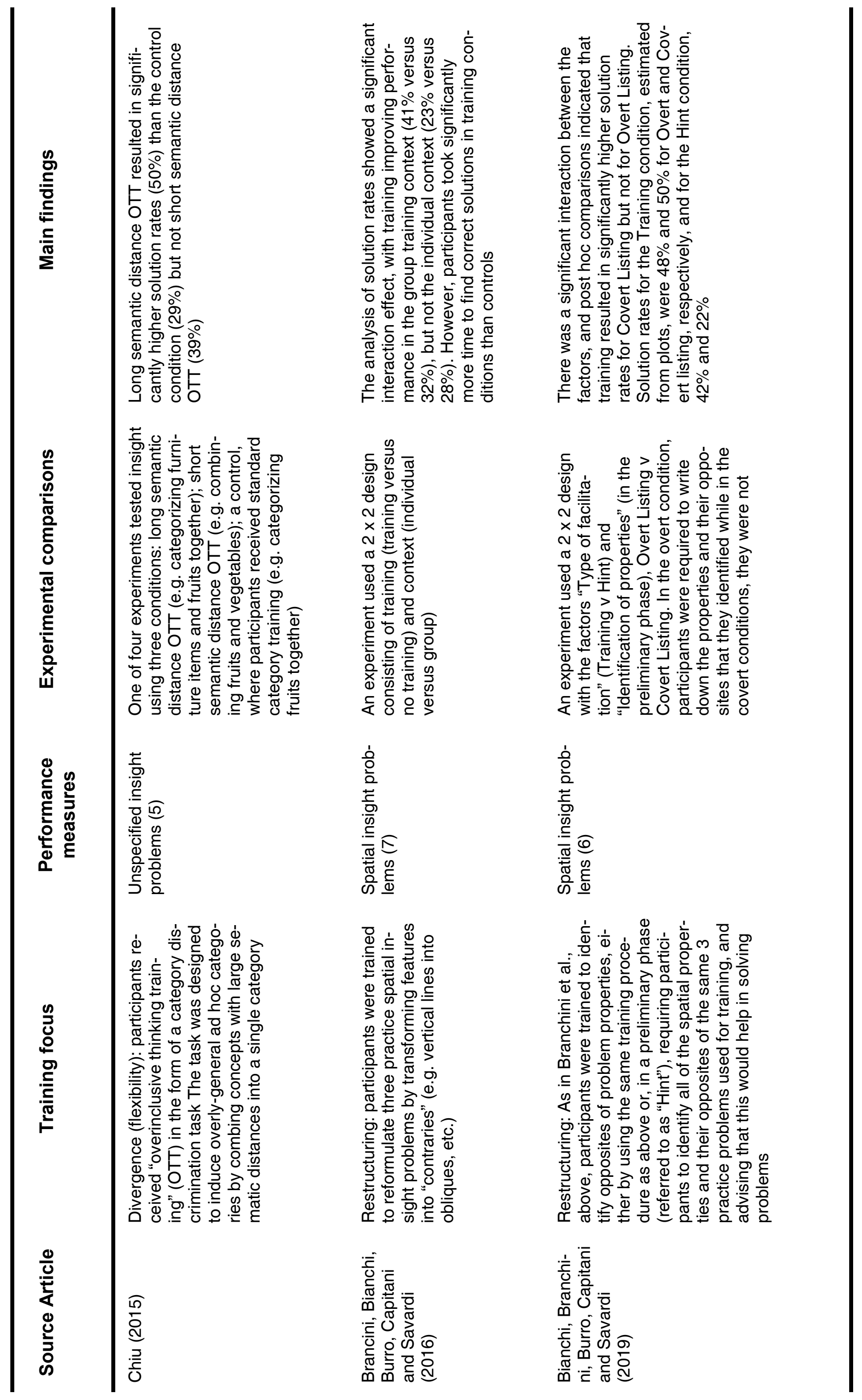


Of the 30 experiments reported, none directly compared the two most common training procedures, restructuring and divergence. This comment is not intended as criticism, since for the most part, studies were concerned with establishing whether or not a training method was effective. The situation is analogous to that of creativity training a generation ago, when it was observed that the focus of research had been on the overall effectiveness of training approaches rather than on the specific factors that led to success (Clapham, 1997). There is now sufficient evidence that insight can be improved by training to ask whether one theoretical approach may be better than another. Both experiments reported below directly compared training methods derived from the different major theoretical traditions, of restructuring and divergent thinking.

The experiments reported here compared a restructuring approach to three divergent thinking procedures based separately on fluency, flexibility and originality, the main factors of divergent thinking. The first experiment compared restructuring training and divergence training with a control condition. The second experiment compared restructuring, flexibility, fluency and originality training.

In addition to similarities and differences in training approach, the 30 experiments reviewed above also showed similarities and differences in the format of instruction. The majority used primarily paper-based instruction (e.g. Ansburg \& Dominowski, 2000; Chrysikou, 2006; Dow \& Mayer, 2004; Duncan, 1961; Patrick \& Ahmed, 2014; Patrick et al., 2015), some provided combined verbal and written instructions (Cunningham \& MacGregor, 2008; Walinga, Cunningham, \& MacGregor, 2011; Davidson \& Sternberg, 1984; Maier, 1933), while one used audio tape (Ostafin \& Kassman, 2012) and one, computerized instruction (Chiu, 2015). Whichever format is used, there is potential for participants to understand instructions differently from intended. Participants may read instructions with different degrees of attention or understanding while instructions presented orally may vary in tone or emphasis, or depart in places from the written script. Whatever the format, there is room for variability in how instructions are received and interpreted by participants. To test whether format influences the effectiveness of training, the first experiment reported below varied delivery format as a second independent variable.

\section{Experiment 1}

The study compared the effects of divergent thinking training and restructuring training on subsequent performance on insight problem solving. The study used an experimental design with participants randomly assigned to one of three treatment groups, divergence (D), restructuring $(R)$ or a control group $(C)$.

Training in divergence in this case focused on fluency, and was based on Clapham's (1997) short-form process for training ideational skills, in which participants were 
shown a variety of idea generation techniques including brainstorming, forced relation, conceptual combination, and elaboration or 'catalog' (Clapham, 1997; Clapham \& Shuster, 1992). The restructuring training combined and elaborated techniques from our previous studies on training insight (Cunningham \& MacGregor, 2008; Walinga, Cunningham, \& MacGregor, 2011) and focused on a variety of insight thinking techniques including problem formulation, drilling down, assumption checking, and recognizing and overcoming barriers. The control training was based on the control condition described by Ansburg and Dominowski (2000), and focused on recalling relevant facts, being systematic and maintaining a focus on the goal.

To test whether delivery format may be a factor in the effects of training, the experiment varied format as a second independent variable.

\section{METHOD}

\section{Participants}

Participants were 61 student volunteers from the University of Victoria, 30 female and 31 male. Age information was not collected.

\section{Materials}

\section{Training phase}

Scripts were developed for each of the three training conditions, designed to be approximately equal in length. The number of words was 430,421 and 431 for the Restructuring, Divergence and Control conditions, respectively. Each script began with the 9 dot problem as an example of the kind of problem that would be presented later, then gave advice related to the form of training, and ended with a list of brief prompts that would be provided as reminders with each test problem. The scripts are provided in Appendix A.

Test phase

Materials for testing consisted of five spatial insight problems taken from Walinga et al., 2011). (See Appendix B.)

\section{Design and Procedure}

The experiment used a 3x2 between subjects design consisting of three levels of training ( $R, D$ and $C$ ) and two levels of presentation format (verbal and written script). Participants were randomly assigned to experimental conditions with the constraint of 10 per cell. One additional volunteer was accidentally scheduled and assigned to the Restructuring condition. Participants were tested individually. After the assigned form of training, the five insight problems were presented individually in the same random order and participants were allowed up to four minutes for each problem. After one minute, unless the participant had already solved a problem, reminder training prompts were given, either orally or in written form, depending on presentation condition. 


\section{RESULTS AND DISCUSSION}

Scores of 1 and 0 were assigned to correct and incorrect solutions and summed across the five problems for each participant. The means (and standard deviations) of the number correct for each condition are shown in Table 2.

Table 2

\section{Mean (and Standard Deviation) of the Number of Problems Solved by Training Condition and Presentation Format, Experiment 1}

\begin{tabular}{lcc}
\hline & \multicolumn{2}{c}{ Presentation Format } \\
Training condition & Verbal & Script \\
\hline Restructuring & $4.20(0.92)$ & $2.91(1.30)$ \\
Divergent & $2.20(1.14)$ & $2.90(1.73)$ \\
Control & $2.70(0.67)$ & $2.70(0.95)$ \\
\hline
\end{tabular}

Total scores were analyzed using ANOVA which indicated a significant main effect of training, $F(2,55)=12.11, M S E=6.05, p<.02, \eta^{2}=.14$, a significant training $x$ presentation interaction, $F(2,55)=3.83, M S E=5.24, p<.03, \eta^{2}=.12$, and no significant effect of presentation, $F(1,55)=.43,=.59, p=.51$. The form of the interaction effect is illustrated in Figure 1, which suggests that there was little difference between conditions when training was delivered by script. Bonferroni tests of simple main effects indicated that restructuring training was significantly more effective than either the fluency training $(p<.001)$ or control conditions $(p<.02)$ for verbal training only. No other differences were significant. While the results supported the effectiveness of the restructuring procedure, they also called into question the effectiveness of a script-based approach to training. This was unexpected, as many previous studies using training scripts have reported successful outcomes (Ahmed \& Patrick, 2006; Ansburg \& Dominowski, 2000; Chrysikou, 2006; Dow \& Mayer, 2004; Kershaw \& Ohlsson, 2004). Based on the results, we conducted a post-hoc power analysis, which indicated that the experiment were underpowered at .71, falling short of the desired criterion of .8. The second experiment developed and tested new training scripts, following the approach of Chrysikou (2006), and based the sample size on a power analysis of the results of that study. 


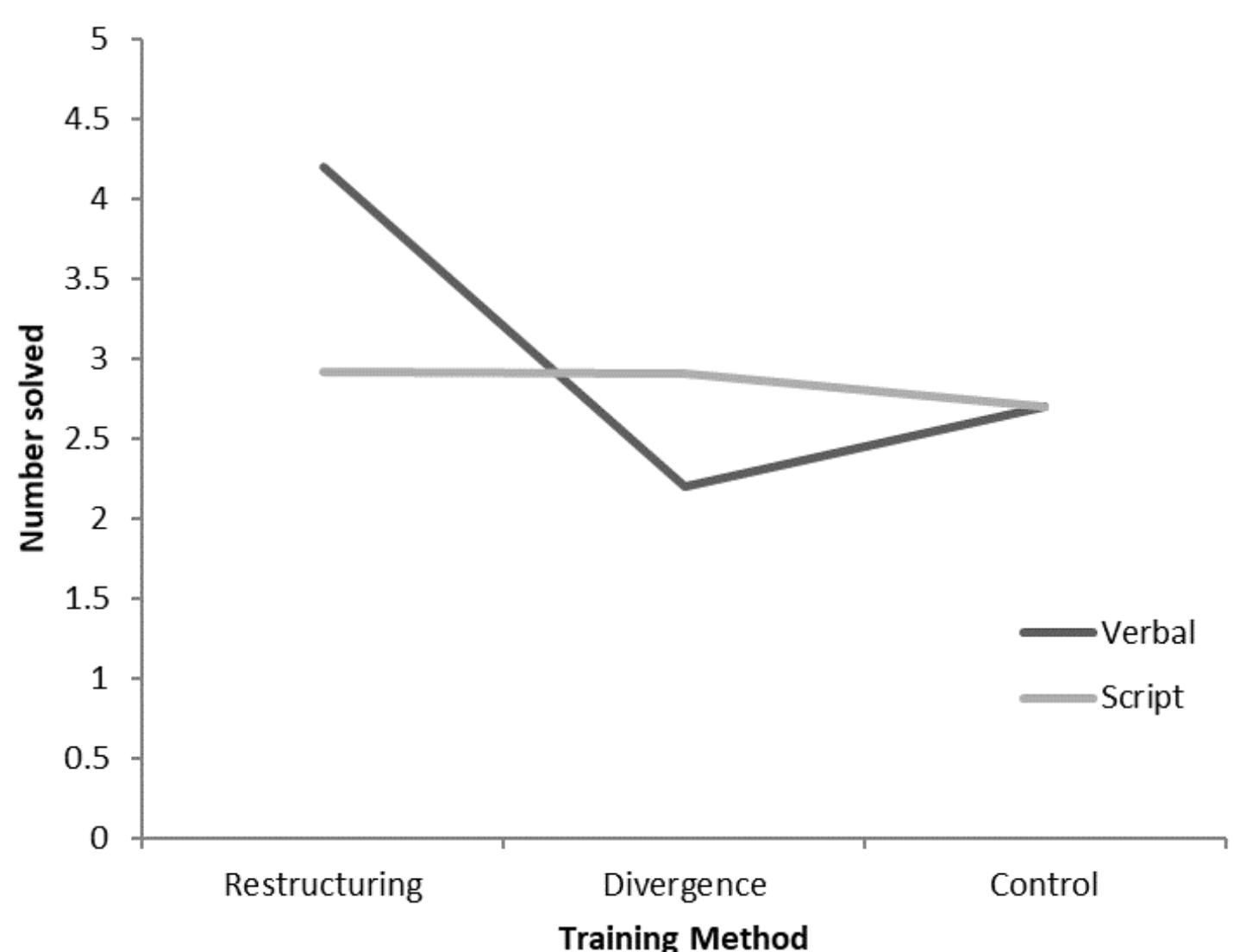

Figure 1. Mean number of problems solved by training method and presentation format

\section{Experiment 2} (verbal or script), Experiment 1

The first experiment failed to find any significant effects when training was delivered in a written format. The result raises the possibility that, to be effective, our restructuring training has to be provided orally. We developed a new script-based approach, which the second experiment tested, comparing it to three other script-based approaches.

The first approach, which we refer to as flexibility training, used the Alternative Categories Test procedure described by Chrysikou (2006), adapted from the Unusual Uses Test of Christensen and Guilford (1958). The procedure consists of a printed questionnaire presenting 12 common objects (e.g. pillow, fork, shoe, brick) and describing a common use for each (e.g. for sleeping, for eating, as footwear, for building, etc.). The task invites participants to list up to six additional purposes to which each object could be put (e.g. a shoe could be used to drink champagne from). The instructions included the example of a newspaper, described as an item for reading, and listed six alternative uses, including "to start a fire" and "to wrap a parcel". Participants were informed that acceptable alternatives must be different from each other and different from the original use.

Our second approach adapted the same procedure to focus on fluency rather than flexibility. Again, the instructions used the example of a newspaper and indicated that the 
task was to think of other items that could be used for reading, such as a book, magazine, article, cereal box, etc. Participants were instructed that each acceptable item must be different from the others but used for a similar purpose, and too think of as many different items as you can in the time given.

We adapted the same procedure to create a third approach with a focus on originality rather than flexibility or fluency. In this case, the alternative uses for the example of "newspaper" included "as a tent" and "as a telescope". Acceptable alternatives were described as having to be different from each other and completely unusual.

The final approach adapted the ACT procedure for restructuring training. In this case, the example given illustrated a cascading series of problems posed by having no newspaper, starting with (1) not knowing the daily news, leading to (2) not being up to date on events, resulting in (2) having nothing to talk about. Example solutions provided for the third, "core", problem were to take books from the library, to learn a new skill, and to travel. The instructions indicated that the process "explores the problem more deeply" and "reframes the problem". The task used the same 12 objects as in the flexibility and originality conditions, but described the initial problem in terms of lacking the object (e.g. no pillow, no fork, etc.). In each case, participants were invited to write three connected problems caused by the lack of the object and a solution to the final "core" problem. For example, having no pillow might lead to poor sleep, leading to lack of concentration during tomorrow's classes, resulting in taking poor lecture notes. The final problem could be solved by borrowing notes from a classmate after the lecture.

\section{METHOD}

\section{Participants}

Participants were 89 volunteers from the University of Victoria and Royal Roads University. Age and gender information were not collected. A power analysis based on the results reported in Table 1 of Chrysikou (2006) indicated a minimum total sample size of 64 .

\section{Materials}

\section{Training phase}

The materials were as described above. The first page of each set of instructions is provided in Appendix C.

\section{Testing phase}

The test phase used the same seven insight problems reported in Chrysikou (2006): the Charlie problem (Weisberg, 1995), the Fake Coin problem (Weisberg, 1995), the Prisoner and Rope problem (Isaak \& Just, 1995), the Candle problem (Isaak \& Just, 1995), the Pyramid and Dollar Bill problem (Isaak \& Just, 1995), the Two-String problem (Isaak \& Just, 1995), and the Ten-Coin problem (Isaak \& Just, 1995). 


\section{Design and Procedure}

The experiment used a between subjects design consisting of four levels of training (Fluency, Flexibility, Originality, Restructuring). Participants were randomly assigned to experimental conditions with the constraint of at least 20 per cell. The assignment resulted in 21 participants in the Fluency condition, 22 in the Flexibility condition, 21 in the Originality condition and 25 in the Restructuring condition. Participants were tested individually. After the assigned form of training, the seven insight problems were presented individually in the same random order and participants were allowed up to eight minutes for each problem. Because Chrysikou (2006) found a significant increase in insight problem solving in the training condition compared with controls, we did not include a control group, and used flexibility performance as a baseline.

\section{RESULTS AND DISCUSSION}

Scores of 1 and 0 were assigned to correct and incorrect solutions and summed across the seven problems for each participant. The means (and standard deviations) were 3.80 (1.78) for restructuring training, 2.67 (1.59) for originality training, 2.14 (1.62) for fluency training and 1.95 (1.50) for flexibility training. One-way ANOVA found a significant difference among means, $F(3,88)=6.14, M S E=2.66, p<.001, \eta^{2}=.18$, while Bonferroni multiple comparison tests indicated that the only significant differences were that restructuring training resulted in significantly more solutions than both fluency training $(p<.01)$ and flexibility training $(p<.001)$.

\section{GENERAL DISCUSSION}

The research reported here was concerned with the training of creativity, specifically, with the training of insight problem solving. As a preliminary, we reviewed meta-analyses and systematic reviews of creativity training, from which it became apparent that (a) the majority of training approaches stressed divergent thinking, and (b) while some reviews included "creative problem solving" as a topic, none singled-out insight problem solving, or reported on whether or not it was amenable to training.

We next conducted a literature search for experimental studies of insight training, which identified 17 articles that met our search criteria, reporting a total of 30 experimental comparisons. In contrast to the general creativity training literature, the majority of these took a restructuring approach (70\%), and a minority, divergent thinking (27\%). For the most part, the experiments compared either single training procedures or related training procedures with a non-training control. This is completely appropriate when the purpose is to establish that a training procedure accomplishes the goal of improving insight performance. However, there are now a sufficient number of experimental demonstrations of the effectiveness of training that it may be time for the goal to shift to one of 
comparing the relative effectiveness of different approaches. The research reported here took this approach, and compared a restructuring approach aimed at overcoming impasses with approaches that focused on the main factors identified as underlying divergent thinking - fluency, flexibility and originality.

The first experiment manipulated two factors orthogonally. The main factor was type of training, with three levels - restructuring training, fluency training, and a control condition. A second factor compared the delivery of training, verbal versus script-based. The majority of prior experiments have used script - based training, although a few have used verbal delivery. Different delivery formats were included to test whether one is more effective than the other, or whether the effect of delivery varies with training approach.

The results indicated a significant training by delivery format interaction, where gestalt - based training was significantly more effective than fluency training or the control in the verbal delivery format but not when training was script - based. The result contrasted with those of several previous studies which had successfully used script-based training, and raised the possibility that our training approach had to be provided orally. To further examine this possibility, Experiment 2 used more extensive scripts based on the procedure described by Chrysikou (2006). We adapted the procedure to provide four different forms of training, focused on fluency, flexibility, originality and restructuring. The procedure for flexibility training was identical to that used by Chrysikou, while the remaining three differed in the goal they assigned to the trainees. In all four cases, the test insight problems were the same as those of Chrysikou. Because Chrysikou found a significant increase in insight problem solving in the training condition compared with controls, we did not include a control group, and used flexibility performance as a baseline.

The results indicated that the scripts used in restructuring approach based on gestalt-based principles resulted in significantly more insight problems solved than either fluency training or the baseline flexibility training, which had the lowest scores of all four procedures. In retrospect, having a control condition would have been valuable, since the findings are consistent with a number of possible outcomes. At one extreme, if our results replicated those of Chrysikou (2006), then all four training conditions improved insight performance. At the other extreme, if flexibility training did not improve performance, then only the restructuring training was significantly effective. Future research will be conducted to further examine these possibilities. For now, however, we can conclude with a degree of confidence that the restructuring training scripts were superior to both fluency and flexibility training.

The studies reported here have a number of limitations, particularly in the case of Experiment 1. As noted previously, the experiment appears to have been underpowered, 
with a consequent concern that it may have failed to detect real differences between conditions. Another potential concern arises from the presence of an instructor in one set of conditions. While the instructor worked from prepared scripts, it is still possible that participants in those conditions received information beyond what was intended. Experiment 2 attempted to correct these deficiencies, by achieving sufficient power and by more stringently controlling the forms of instruction.

There are many other possibilities for research comparing training approaches. There was considerable diversity within the categories of procedures classified as "restructuring" and "divergence" in Table 1. For example, as well as the more traditional forms of instructional training (Ansburg \& Dominowski, 2000; Cunningham \& MacGregor, 2008) there were training procedures based on mindfulness (Ostafin \& Kassman, 2012) and "thinking in opposites" (Brancini et al., 2016; Bianchi et al., 2019). Similarly, in addition to well-established methods for facilitating divergent thinking, the list included a test of "overinclusive thinking" (Chiu, 2015). Comparing different approaches within theoretical categories as well as between may help in further refining training procedures and defining the principles that underlie them.

\section{REFERENCES}

Ahmed, A., \& Patrick, J. (2006). Making implicit assumptions explicit in verbal insight problem solving. Proceedings of the 28th Annual Conference of the Cognitive Science Society, 955-960.

Ansburg, P. I., \& Dominowski, R. L. (2000). Promoting insightful problem solving. Journal of Creative Behavior, 34, 30-60.

Ash, I. K., \& Wiley, J. (2006). The nature of restructuring in insight: An individualdifferences approach. Psychonomic Bulletin \& Review, 13, 66-73.

Ball, L. J., \& Stevens, A. (2009). Evidence for a verbally-based analytic component to insight problem solving. Chapter in N. Taatgen \& H. van Rijn, J. (Eds.), Proceedings of the Thirty-First Annual Conference of the Cognitive Science Society. Cognitive Science Society.

Berardi-Coletta, B., Dominowski, R. L., Buyer, L. S., \& Rellinger, E. R. (1995). Metacognition and problem solving: A process-oriented approach. Journal of Experimental Psychology: Learning, Memory, and Cognition, 21, 205-223.

Bianchi, I., Branchini, E., Burro, R., Capitani, E., \& Savardi, U. (2019) Overtly prompting people to "think in opposites" supports insight problem solving, Thinking \& Reasoning, DOI: $10.1080 / 13546783.2018 .1553738$ 
Brancini, E., Bianchi, I., Burro,R., Capitani, E., \& Savardi, U. (2016) Can contraries prompt intuition in insight problem solving? Frontiers in Psychology, 7, doi: 10.3389/ fpsyg.2016.01962

Bowden, E. M., \& Jung-Beeman, M. (2003). Normative data for 144 compound remote associates problems. Behavioral Research Methods, Instruments and Computers, 35: 634-639.

Burke, R. J., Maier, N. R., \& Hoffman, R. (1966). Functions of hints in individual problem solving. American Journal of Psychology, 79, 389-399.

Christensen, P. R., \& Guilford, J. P. (1958). Creativity/Fluency Scales. Beverly Hills, CA: Sheridan Supply.

Chronicle, E. P., Ormerod, T. C., \& MacGregor, J. N. (2001). When insight just won't come:

The failure of visual cues in the nine-dot problem. Quarterly Journal of Experimental Psychology, 54A, 903-919.

Chrysikou, E.G. (2006). When shoes become hammers: Goal-derived categorization training

enhances problem solving performance. Journal of Experimental Psychology: Learning,

Memory, and Cognition, 33, 935-942.

Chiu, F-C. (2015). Improving your creative potential without awareness: Overinclusive thinking training. Thinking Skills and Creativity, 15, 1-12

Chu, Y., \& MacGregor, J.N. (2011). Human Performance on Insight Problem Solving: A Review. Journal of Problem Solving, 3(2), 119-150.

Clapham, M.M. (1997). Ideational skills training: A key element in creativity training programs. Creativity Research Journal, 10, 33-44.

Clapham, M.M., \& Shuster, D.H. (1992). Can engineering students be trained to to think more creatively? Journal of Creative Behavior, 26, 156-162.

Cunningham, J. B., \& MacGregor, J. N. (2008) Training insightful problem solving: EffectsO

of realistic and puzzle-like contexts. Creativity Research Journal, 20, 291-296.

Davidson, J. E., \& Sternberg, R. A. (1984). The role of insight in intellectual giftedness. Gifted Child Quarterly, 28, 58-64.

de Bono, E. (1971). Lateral thinking for management. New York: McGraw-Hill.

de Bono, E. (1992). Serious creativity: Using the power of lateral thinking to create new ideas. New York: Harper Collins.

Dow, G. T., \& Mayer, R. E. (2004). Teaching students to solve insight problems: Evidence for domain specificity in creativity training. Creativity Research Journal, 16, 389-402. 
Duncan, C. P. (1961). Attempts to influence performance on an insight problem. Psychological Reports, 9, 35-42.

Gick, M. L., \& Holyoak, K. J. (1980). Analogical problem solving., Cognitive Psychology, 12, 306-355.

Guilford, J.P. (1950). Creativity. American Psychologist, 5, 444-454.

Hume, S.E., (2001). Frederick Banting: Hero, healer, artist. Montreal: XYZ Publishing.

Isaak, M. I., \& Just, M. A. (1995). Constraints on thinking in insight and invention. In R. J. Sternberg \& J. E. Davidson (Eds.), The nature of insight. Cambridge, MA:MIT Press.

Kershaw, T. C., \& Ohlsson, S. (2004). Multiple causes of difficulty in insight: The case of the nine-dot problem. Journal of Experimental Psychology: Learning, Memory, and Cognition, 30, 3-13.

Knoblich, G., Ohlsson, S., Haider, H., \& Rhenius, D. (1999). Constraint relaxation and chunk decomposition in insight problem solving. Journal of Experimental Psychology: Learning, Memory \& Cognition, 25, 1534-1555.

Kokinov, B., Hadjiilieva, K. \& Yoveva, M. (1997). Is a hint always useful in problem solving? The influence of pragmatic distance on context effects. Proceedings of the 19th Annual Conference of the Cognitive Science Society, p, 974. Erlbaum.

Kounios, J., Frymiare, J. L., Bowden, E. M., Fleck, J., Subramaniam, K., Parish, T. B., \& Jung- Beeman, M. (2006). The prepared mind: Neural activity prior to problem presentation predicts subsequent solution by sudden insight. Psychological Science, 17(10), 882-890.

Luo, J., Niki, K., \& Phillips, S. (2004). Neural correlates of the 'Aha !' reaction. NeuroReport For Rapid Communication of Neuroscience Research, 15, 2013-2017.

Luchins, A.S., \& Luchins, E.H. (1970). Wertheimer's Seminars Revisited: Problem Solving and Thinking. State University of New York at Albany.

Lung, C.-T., \& Dominowski, R. L. (1985). Effects of strategy instructions and practice on nine-dot problem solving. Journal of Experimental Psychology: Learning, Memory, \& Cognition, 11, 804-811.

Maier, N. R. F. (1933). An aspect of human reasoning. British Journal of Psychology, 24, 144-155.

MacGregor, J. N., Ormerod, T. C., \& Chronicle, E. P. (2001). Information processing and insight: A process model of performance on the nine-dot and related problems. Journal of Experimental Psychology: Learning, Memory, and Cognition, 27, 176-201.

$\mathrm{Ma}, \mathrm{H}-\mathrm{H}$. (2006). Synthetic analysis of the effectiveness of single components and packages in creativity training programs. Creativity Research Journal, 18, 435-446 
Maltzman, I., Lloyd, B.O., Bogartz, W., \& Summers, S.S. (1958). The facilitation of problem solving by prior exposure to uncommon responses. Journal of Experimental Psychology, 56, 399-406.

Mansfield, R.S., Busse, T.V., \& Krepelka, E.J. (1978). The effectiveness of creativity training. Review of Educational Research, 48, 517-536

Metcalfe, J. (1986). Premonitions of insight predict impending error. Journal of Experimental Psychology: Learning, Memory, and Cognition, 12, 623-634.

Moga E., Burger, K., Hetland, L., \& Winner, E. (2000). Does studying the arts engender creative thinking? Evidence for near but not far transfer. The Journal of Aesthetic Education, 34, 91-104.

Ohlsson, S. (1984). Restructuring revisited: II. An information-processing theory of restructuring and insight. Scandinavian Journal of Psychology, 25, 117-129.

Ohlsson, S. (1992). Information processing explanations of insight and related phenomena. In M. Keane \& K. J. Gilhooley (Eds.), Advances in the psychology of thinking (pp. 1-44). London: Harvester Wheatsheaf.

Ohlsson, S. (2011). Deep learning: How the mind overrides experience. New York, NY: Cambridge University Press.

Ormerod, T. C., Fioratou, E., Chronicle, E. P., \& MacGregor, J. N. (2006). The remnants of insight. Proceedings of the 28th Annual Conference of the Cognitive Science Society, 1893-1898.

Ostafin B.D., \& Kassman, K.T. (2012). Stepping out of history: Mindfulness improves insight problem solving. Consciousness and Cognition, 21, 1031-1036

Patrick, J., \& Ahmed, A. (2014). Facilitating representation change in insight problems through training. Journal of Experimental Psychology: Learning, Memory, and Cognition, 40, 532-543.

Patrick, J., Ahmed, A., Smy, V., Seeby, H., \& Sambrooks, K. (2015). A cognitive procedure for representation change in verbal insight problems. Journal of Experimental Psychology: Learning, Memory, and Cognition, 41, 746-759.

Rose, L. H., \& Lin, H. T. (1984). A meta-analysis of long-term creativity training programs. Journal of Creative Behavior, 18, 11-22.

Scott, G. L., Leritz, L. E., \& Mumford, M. D. (2004). The effectiveness of creativity training: A meta-analysis. Creativity Research Journal, 16, 361-388.

Torrance, E. P. (1972). Can we teach children to think creatively? Journal of Creative Behavior, 6, 114-143.

Walinga, J., Cunningham, J.B., \& MacGregor, J.N. (2011). Training insight problem solving through focus on barriers and assumptions. Journal of Creative Behavior, 45, 47-58. 
Weisberg, R. W. (1995). Prolegomena to the theories of insight in problem solving: A taxonomy of problems. In R. J. Sternberg \& J. E. Davidson (Eds.), The nature of insight (pp. 157-196). Cambridge, MA: MIT Press.

Wen, M-C., Butler, L.T., \& Koutstaal, W. (2012). Improving insight and non-insight problem solving with brief interventions. British Journal of Psychology, 4, 97-118.

Wicker, F. W., Weistein, C. E., Yelich, C. A., \& Brooks, J. D. (1978). Problemreformulation training and visualization training with insight problems. Journal of Educational Psychology, 70, 372-377.

\section{APPENDIX A}

\section{Training for Experiment 1}

The initial training involved reviewing a sample problem (nine-dot problem). After an introduction, the experimenter illustrated the problem and the correct solution and the principles that would be used for solving the problem for each of the conditions: Fluency, restructuring focus and control.

The fluency training encouraging people to think of principles based on developing more ideas in solving the nine-dot problem using phrases like "One way is to let ideas run wild and suspend judgment of ideas", "Are there ways to magnify, minify, or rearrange ideas that you already have?" Subjects were reminded that these types of problems may require you to combine ideas, broaden your thinking, or view the problem in different ways.

They were informed that they would get reminders through the session:

- How many ideas or solutions can you generate right now about this problem? Be sure you are withholding any adverse judgment until later, anything goes, nothing is too outrageous! How many wild, untamed, unusual, out of the box ideas can you think of for this problem? Can you generate even more ideas? Are there any you haven't thought of yet?

- When you look at some of the ideas you have generated, can any of them be combined, connected, or improved in some way to generate even more ideas? What are some combinations or constructions that you have not considered yet because they are too unusual? Are there ways to magnify, minify, or rearrange ideas that you already have?

- What are some other ways you might look at this problem? What are some other perspectives you might take on when looking at this problem? Who might come at this problem a little differently? Can you imagine how they might approach it differently?

- Is there a common principle here that could be applied to all of the problems? What other problems does this problem remind you of? Is there anything in the room that might spur further ideas? 
The Restructuring Focus Training involved helping principles to help people recognize that this type of problem is difficult is because people place unnecessary limits on themselves. They make assumptions about what or isn't allowed that stops them from finding the answer. Examples of assumptions include: "you have to stay inside the "square". No, you can go "outside of the box", "lines have to be vertical or horizontal" and "you have to connect dots and you can start a line where there is no dot". In this problem, we might fixate on assumptions, and the barriers these create, rather than solving the core challenge of a task. Revealing barriers and assumptions can help you to identify the real challenge rather than trying to 'make more lines or get rid of dots.'

Solving these types of problems may require you to reveal the barriers and assumptions you are constructing, find the core challenge, and reformulate the problem in more insightful ways. Some of the reminders throughout the session included:

- What have you tried so far?

- What is getting in the way? What do you find yourself focusing on?

- Because what are you assuming? What if your assumption is incorrect? Does it have to be that way?

- What is getting in the way? What is making you most uncomfortable or irritated; what bothers, concerns, bugs you most? What is the real problem you are trying to solve here?

- What is making that difficult? What concerns you about that?

- What is most important then? What is the real challenge here? You need to in order to ?

- What are some solutions you can think of to solve the real challenge you have just identified?

The Control Training suggested that problems like this are difficult for various reasons including: knowledge required, complexity, or inability to recognize the goal we want to obtain. That is, one source of difficulty may be the failure to use our knowledge. Finding the solution might require recalling a relevant fact, and failure to solve the problem may be nothing more than failure to remember. Some problems are difficult because they are too large - there are so many alternatives to consider that it can be difficult to explore them all and to keep track of which ones we have tried vs. which ones still need to be checked. To succeed on such problems a person needs to systematically consider alternatives and keep good (mental or physical) records of which ones have been tried. For instance, the nine dot problem you just tried could be solved eventually by going through the various possibilities and tracking these until you found a solution. Also, we tend to lose sight of 
the goal of the task. The goal becomes 'joining up all the dots' when really the goal involves 'drawing 4 straight lines through each of the 9 dots below.' We often end up focusing on the wrong goal.

Some of the reminders during the session included:

- What principle or fact may you not be remembering? What specialized knowledge may be required? Can you delve into and scan your memory for other facts and principles that you know, but may simply be struggling to remember right here and now? What principles or facts may you not have considered yet?

- $\quad$ Are you able to keep track of this problem? How might you work through this problem more systematically?

- When you think about what you are focusing on trying to do right now, are you focusing on the right goal? What is the goal of the task again?

\section{APPENDIX B}

\section{Test insight problems (Experiment 1)}

Task required

Illustration of materials

1. Cards: Materials: Twelve cards from a standard deck, four Kings, Queens, Jacks.

The task is to arrange them in a grid -a table-so that each row and each column contains only one Jack, one Queen and one King. Source: Cunningham and MacGregor (2008)

2. Hexagon: Materials: 12 discs and Hexagon The task is to arrange the 12 discs so that each side of the hexagon has 4 discs? Source: Cunningham, MacGregor, Gibb, and Harr (2009)

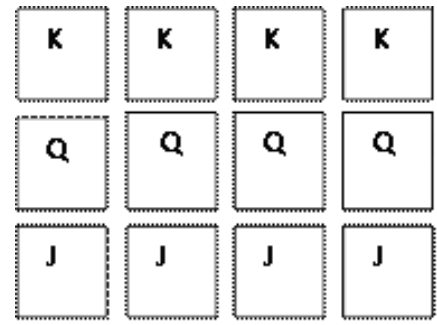

00000

10000

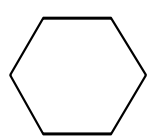

3. Cross: Materials: Five pieces of wood (as shown on right). The task is to arrange the 5 pieces to form a cross (like a plus sign). Source: Adapted from the $T$ -puzzle, Suzuki, Abe, Hiraki, and Miyazaki (2001)

4. Sticks. Materials: 8 matchsticks.

The task is to move three sticks and change the pattern on the left to look like the pattern on the right? Source: Adapted from Kokinov et al., (1997)
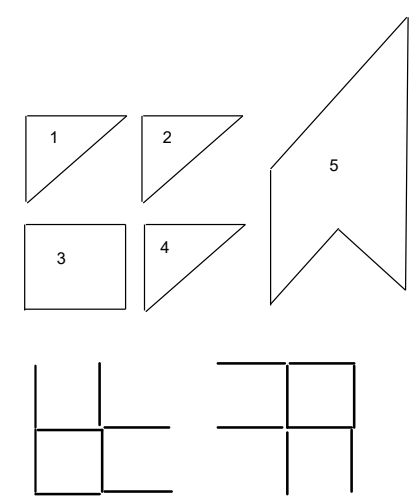

5. Diagram of pigs in a pigpen.

The task is to add two squares so that each of the 9 pigs ends up in a separate enclosure. Source: Gilhooly and Murphy (2005); Isaak and Just (1996)

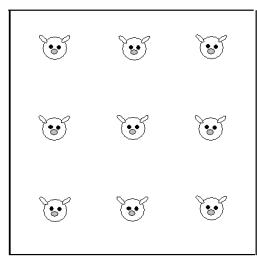




\section{APPENDIX C}

\section{Training scripts for Experiment 2}

This training involved completing 12 tasks where participants were given 15 minutes to complete. Each task required participants to read the instructions aloud and complete the task.

\section{Fluency Training}

In this fluency task, the participant was asked to list as many different items that may be used for the same purpose as the original item.

\section{EXAMPLE:}

Given: A NEWSPAPER (used as reading material)

You might think of the following other items that can be used for the same thing:

- book

- $\quad$ magazine

- $\quad$ article

- $\quad$ cereal box

- $\quad$ advertisement

- play

- $\quad$...

- $\quad \cdots$

- $\quad$ Etc...

They are asked to recognized that all of the items listed are different from each other but used for a similar purpose. Each acceptable item must be different from the others but used for a similar purpose. They are asked to think of as many different items as you can in the time given.

\section{Flexibility Training}

In this task, there were several common items and participants were asked to list as many as six (6) other categories to which the items could belong.

EXAMPLE:

Given: A NEWSPAPER (Common use: Item for reading).

You might think of the following other categories in which a newspaper would belong:

1. Things to start a fire

2. Things to wrap parcels

3. Item to swat flies

4. Item to use as stuffing to pack boxes

5. Something to line drawers or shelves

6. Use the letters to make up a kidnap note 
They are asked to notice that all of the categories listed are different from each other and different from the primary use of a newspaper. Each acceptable category must be different from others and different from the common category.

\section{Originality Training}

In this task, participants were asked to consider some common items and to imagine other unusual purposes it might hold.

\section{EXAMPLE:}

Given: A NEWSPAPER (used for reading material)

You might think of the following other completely unusual uses for this item:

1. tent

2. paper maché

3. food

4. $\quad$ skirt

5. pom poms

6. telescope

They are asked to notice that all of the items listed are very different from each other and completely unusual uses for the item. Each acceptable item must be very different from the others and completely unusual uses for the original item. Think of as many different items as you can in the time given.

\section{Restructuring Focus Training}

When we are faced with tough problems it can be difficult to frame the problem correctly. Sometimes we jump to conclusions or make assumptions about the nature of a problem which leads us down the wrong path and can get us stuck. When we explore the problem more deeply and peel back the layers we can frame it correctly and find more insightful solutions.

\section{EXAMPLE:}

Given: NO NEWSPAPER

What if you can't get a newspaper? The problem this might cause is I can't get the daily news

And what if you can't get the daily news? The problem is I won't be up to date on events And what if you can't be informed? The problem is I won't have much to talk about How can you solve this core problem without a newspaper?

1. Take out books from the library

2. Communicate more with others 
3. Use the internet

4. Do something else which I can learn things from

They are asked to notice that the above process explores the problem more deeply and reframes the problem. Each acceptable item must explore the problem more deeply and reframes the problem

Corresponding author at: J. Barton Cunningham, School of Public Administration University of Victoria, PO Box 1700 STN CSC, Victoria, BC V8W 2Y2, Canada.

E-mail: bcunning@uvic.ca 